\title{
GH deficiency after traumatic brain injury: improvement in quality of life with GH therapy: analysis of the KIMS database
}

\section{Chris J Gardner, Anders F Mattsson ', Christina Daousi, Márta Korbonits², Maria Koltowska-Haggstrom ${ }^{3}$ and Daniel J Cuthbertson}

Department of Obesity and Endocrinology, Institute of Ageing and Chronic Disease, University of Liverpool, Liverpool L9 7AL, UK, ${ }^{1}$ Pfizer Endocrine Care, Pfizer, Inc., Sollentuna, Sweden, ${ }^{2}$ Barts and the London School of Medicine and Dentistry, William Harvey Research Institute, Centre for Endocrinology, Queen Mary University of London, London, UK and ${ }^{3}$ Department of Women's and Children's Health, Uppsala University, Uppsala, Sweden
Correspondence should be addressed to D J Cuthbertson Email daniel.cuthbertson@ liverpool.ac.uk

\begin{abstract}
Objective: Prevalence of GH deficiency (GHD) caused by traumatic brain injury (TBI) is highly variable. Short-term studies show improvement in quality of life (QoL) during GH replacement (GHR), but long-term data are lacking. The aim of this study was to analyse the clinical characteristics of post-traumatic hypopituitarism and the QoL effects of long-term GHR. Design/methods: Pfizer International Metabolic Database patients with GHD caused by TBI and by non-functioning pituitary adenoma (NFPA) were compared regarding: clinical characteristics at baseline and 1-year of GHR, and QoL response up to 8-years of GHR (QoL-AGHDA total scores and dimensions) in relationship with country-specific norms.

Results: TBI patients compared with NFPA patients were younger, diagnosed with GHD 2.4 years later after primary disease onset $(P<0.0001)$, had a higher incidence of isolated GHD, higher GH peak, a more favourable metabolic profile and worse QoL, were shorter by $0.9 \mathrm{~cm}(1.8 \mathrm{~cm}$ when corrected for age and gender; $P=0.004)$ and received higher $\mathrm{GH}$ dose (mean difference: $0.04 \mathrm{mg} /$ day $P=0.006$ ). In TBI patients, 1-year improvement in QoL was greater than in NFPA (change in QoL-AGHDA score 5.0 vs 3.5, respectively, $P=0.04$ ) and was sustained over 8 years. In TBI patients, socialisation normalised after 1 year of GHR, self-confidence and tenseness after 6 years and no normalisation of tiredness and memory was observed. Conclusion: Compared with NFPA, TBI patients presented biochemically with less severe hypopituitarism and worse QoL scores. GHR achieved clinically relevant, long-term benefit in QoL.
\end{abstract}

\section{Introduction}

There is evidence to demonstrate that following a traumatic brain injury (TBI), patients are at significant risk of developing post-traumatic hypopituitarism (PTHP) $(1,2,3,4,5,6,7,8,9,10,11,12,13,14)$. Following TBI, patients have significantly reduced quality of life (QoL) and cognitive indices $(15,16)$. Symptoms of fatigue are further exacerbated in the presence of growth hormone (GH) deficiency (GHD) compared with patients with normal GH reserve (17). These functional outcomes, together with PTHP, have been associated with abnormal neuroimaging findings in
TBI patients (18). Cognition and mood can be improved with GH replacement (GHR), with benefits shown after 1 year of therapy $(19,20)$. However, little is known about long-term changes in QoL following GHR in this population, with only one study reporting improvements in QoL (21). Furthermore, data are lacking about the impact of GHR on body composition and metabolic profiles, both of which are known to improve in other patient groups following GHR.

Studies that address how common this problem is have revealed widely differing estimates of the prevalence

Published by Bioscientifica Ltd. 
rates of PTHP, partly because of variation in the definitions of GHD, the use of different provocation tests to diagnose GHD and different time points for assessing pituitary function post-TBI $(12,22)$. Furthermore, results of several dynamic function tests are dependent on the BMI of the patient (23), therefore confounding the data.

Despite the high prevalence of PTHP reported in some studies, a review of the Pfizer International Metabolic (KIMS) database by Casanueva et al. (24) in 2005 highlighted only 51 KIMS patients with adult-onset PTHP compared with 688 KIMS patients with GHD following non-functioning pituitary adenoma (NFPA). Subsequent to this, a further interrogation of the German KIMS database in October 2006 found 69 cases of GHR for this indication (25). These data may suggest deficiencies in the neuroendocrine evaluation of patients after TBI and potentially a very high prevalence of undiagnosed and symptomatic TBI-related GHD and hypopituitarism. It should be highlighted that only patients receiving GHR are followed in the KIMS database, and therefore alternative explanations could account for the lack of patients: either these TBI patients do not receive GH therapy or they have not been registered on the KIMS database.

The aim of the current study was to utilise the KIMS database to examine: i) the secular trends in numbers of new KIMS patients with PTHP; ii) the metabolic profile and associated defects of patients with PTHP; and iii) the effect of GHR on QoL measures over an extended period to assess the degree of long-term response. We used patients treated for NFPA as a comparator group.

\section{Patients and methods}

\section{Patient groups}

In August 2012, the KIMS database (a pharmaco-epidemiological survey of adult hypopituitary patients with GHD; total number of KIMS patients $=16$ 266) (26) was interrogated for all patients with a diagnosis of TBI (Fig. 1). Diagnosis was recorded based on the clinical history taken by the registering physician. In this study, three different groups were analysed: i) all patients with TBI for the assessment of trends in the registrations of PTHP (Group 1, $n=479$ ); ii) patients with TBI, diagnosed with adult-onset GHD, never treated with GH before entry into KIMS and who had baseline and a minimum of 12-month follow-up data for the 1-year analysis of changes in metabolic profile and QoL (Group 2, $n=161$ ); and iii) patients with TBI, diagnosed with adult-onset GHD, never treated with GH

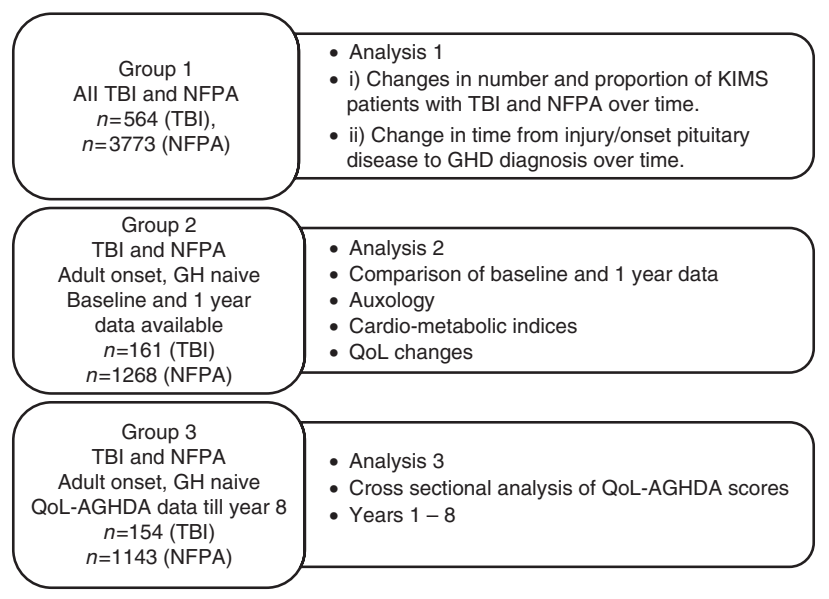

\section{Figure 1}

Investigation algorithm demonstrating inclusion criteria and analyses performed.

before entry into KIMS, with reported QoL-AGHDA up to 8 -year follow-up for the cross-sectional internal reference analysis of QoL (Group 3, $n=154$ ). For the external reference analyses comparing the normal population, a subgroup of 126 patients was selected due to availability of reference data from Belgium, France, Germany, The Netherlands, Spain, Sweden and the UK. Patients with more than one pituitary diagnosis were excluded. Patients diagnosed with GHD in adulthood due to a TBI sustained in childhood were included.

Data from all patients with a diagnosis of adult-onset GHD caused by NFPA and no reports of cranial irradiation, who had baseline and a minimum of 12-month follow-up data, were used as a reference group. There were 1268 eligible NFPA patients for 1-year longitudinal analysis and a maximum number of 1143 NFPA patients from the same countries as TBI patients with QoL data at entry into KIMS for cross-sectional QoL analysis. All patients commencing GHR were required to be on complete replacement of other pituitary hormones and on stable doses before commencement of GHR.

\section{Assessments}

Three separate analyses were performed:

In the first analysis, in order to ascertain whether the number of KIMS patients with TBI were increasing, the database was interrogated for all registrations from inception in 1994-2009 (Fig. 1). In order to ascertain relative proportions, this number was expressed as 
percentage of the total number of registrations. Additionally, in patients with an injury date/onset of pituitary disease, the age at onset was compared with age at diagnosis of GHD to ascertain the lag time from injury to diagnosis in both TBI and NFPA (Group 1).

In the second analysis, patients with TBI and NFPA were compared at baseline and 1-year follow-up (Group 2). Data analysed included demographic characteristics, number of associated pituitary deficiencies, stimulation test used, GH peak, insulin-like growth factor 1 (IGF1)SDS, height, weight, BMI, cholesterol, HDL-cholesterol (HDL), LDL-cholesterol (LDL), triglycerides, lean body mass (bioimpedence (BIA)), fat mass (BIA), systolic and diastolic blood pressure, fasting glucose, HbA1c and total QoL-AGHDA score. This analysis was carried out on the database not only as a whole, but also on a subgroup of patients with 'severe' GHD defined as:

i) $\mathrm{GH}$ peak $<3 \mu \mathrm{g} / \mathrm{l}$ during insulin tolerance test or glucagon stimulation, or

ii) suboptimal BMI-dependent GH peak during GHRHArginine stimulation according to international guidelines, BMI $<25$ and $\mathrm{GH}$ peak $<11.5 \mathrm{ng} / \mathrm{ml}$, BMI 25-30 and GH peak $<8 \mathrm{ng} / \mathrm{ml}, \mathrm{BMI}>30$ and GH peak $<4.2 \mathrm{ng} / \mathrm{ml}(27)$, or

iii) IGF1-SDS $<-2$ in combination with three or more additional pituitary hormone deficiencies.

In the third analysis, QoL-AGHDA scores in patients with TBI and NFPA were analysed cross-sectionally in relationship with country-specific normative values up to 8 years of KIMS follow-up (Group 3).

The QoL-AGHDA, a disease-specific instrument, consists of 25 items that evoke yes/no answers, acknowledging or denying certain problems (28). QoL-AGHDA score is scored from 0 (best QoL) to 25 (worst QoL). A numerical decrease in the QoL-AGHDA score indicates an improvement in QoL. The instrument is reliable and valid with a high level of internal consistency (29). The normative reference values for the QoL-AGHDA were derived from general population samples from seven European countries $(30,31,32,33)$.

The analysis was also performed for the following QoL-AGHDA dimensions: problems with memory and concentration (six items), tiredness (seven items), tenseness (three items), social isolation (five items) and problems with self-confidence (four items), and the results presented as proportion of items with impairment within each dimension (33).

Serum IGF1 and lipids were centrally analysed at Kabi Pharmacia (Stockholm, Sweden) (1994-1997), and thereafter at Sahlgrenska University Hospital, Gothenburg, Sweden. The following assay methods were used: until November 2002, RIA after acid/ethanol precipitation of IGF-binding proteins (Nichols Institute Diagnostic, San Juan Capistrano, CA, USA); until September 2006, chemiluminiscence immunoassay (Nichols Advantage System); and after September 2006, Immulite 2500 (DPC Siemens, Munich, Germany) (34). Intra-assay, inter-assay, and total coefficients of variation were $<9 \%$ in the concentration range of $125-1046 \mu \mathrm{g} / \mathrm{l}$. The assay detection limit was $13.5 \mu \mathrm{g} / \mathrm{l}$. Age and gender-specific reference ranges were used to determine an IGF1-SDS for each patient (35). Serum total cholesterol, HDL-cholesterol and triglycerides were measured by standardised methods and serum LDL-cholesterol was calculated according to the Friedewald formula (36). Waist and hip measurements were conducted according to KIMS Guidelines (36), and BMI was calculated as body weight $(\mathrm{kg}) /(\text { height })^{2}\left(\mathrm{~m}^{2}\right)$.

\section{Statistical analysis}

Descriptive statistics were presented and analysed with means and S.D., or proportions, depending on the type of variable. Regression analysis on time between TBI date or date of diagnosis of NFPA and diagnosis of GHD was adjusted for age (numerical), gender, calendar-year (numerical) and were performed by PROC REG, SAS version 9.2 .

The statistical analyses for baseline outcome variables and 1-year change outcome variables were performed by covariance analyses for unbalanced designs (PROC GLM, SAS version 9.2). Group comparisons, using mean values, were adjusted, in general, for age at measurement and gender, except for the analysis of GH peak, which additionally were adjusted for type of stimulation test. As these adjusted means are assumed to vary with age and gender, we chose to present them for both study groups at a typical (KIMS entry) age of 45 years with equal gender distribution. For the analyses of dimensions of QoL-AGHDA, mixed-linear regression was used as the within-patient dimension scores are expected to correlate. The number of items differed by dimension, so standardisation was necessary and this was achieved by computing the percentage of items within a dimension that a patient expressed problems with. The covariance structure was estimated with an unstructured variance-covariance matrix. Adjustments were made for age and gender. Analyses were performed at yearly visits (cross-sectionally). CIs were Wald based. Statistical significance was set to $P<0.05$. 


\section{Results}

\section{Analysis 1 (Group 1)}

See supplementary data section.

\section{Analysis 2 (Group 2)}

Differences in baseline profiles $~-$ For the analysis of metabolic profile and QoL baseline characteristics in Group 2 - adult-onset GHD patients (161 TBI and 1268 NFPA patients) are given in Table 1 . TBI patients were younger; however, there was no difference in gender distribution with a male preponderance in both groups. TBI patients were shorter than NFPA patients by $0.9 \mathrm{~cm}$ $(1.8 \mathrm{~cm}$ when corrected for age and gender; $95 \% \mathrm{CI}:-3.0$ to $-0.6 \mathrm{~cm} ; P=0.004)$.

Body composition was similar in both groups, with the exception of a reduction in lean mass in the TBI group. Metabolic indices were more favourable in the TBI group even after correction for age and gender with lower systolic and diastolic blood pressure, and total cholesterol and LDL (Table 2).

Despite similar IGF1-SDS in both groups, peak GH was greater in the TBI patients after adjustment for age, BMI, gender and stimulation test $(P=0.02)$ when the group was considered as a whole. Proportions of GH stimulation tests by group are shown in Fig. 2.

TBI patients had fewer associated pituitary deficiencies (1.6; $95 \%$ CI: $1.4-1.8$ for TBI vs 2.4 ; $95 \%$ CI: $2.3-2.5$ for NFPA) and a higher prevalence of isolated GHD (24.9\% TBI vs $6.4 \%$ NFPA). The most frequent additional deficiency was adrenocorticotrophin deficiency in both groups, followed by TSH, LH/FSH and ADH in TBI patients, and LH/FSH, TSH and ADH in NFPA. QoL-AGHDA score was statistically significantly worse in TBI patients compared with NFPA patients. This was consistent across all QoLAGHDA subdomains of memory, tiredness, tenseness, socialising and self-confidence (data not shown).

One year follow-up data $>$ Follow-up data for both TBI and NFPA patients are given in Table 1. Improvements were seen in IGF1-SDS and waist-to-hip ratio in both groups; however, improvements were also seen in body composition in the NFPA group with an increase in lean mass, which was not seen in the TBI group. Likewise, NFPA patients saw marginal increases in fasting glucose and $\mathrm{HbA} 1 \mathrm{c}$ with reductions in total cholesterol, LDL and triglycerides. There were no statistically significant between group changes in any of these variables. Mean GH dose over the 12-month period was somewhat higher in the TBI group $(0.37 \mathrm{mg} /$ day vs $0.33 \mathrm{mg} /$ day for NFPA patients (mean difference: $0.04 \mathrm{mg} /$ day 95\% CI: 0.01-0.07; $P=0.006$; adjusted for age and gender).

Assessment of QoL: total QoL-AGHDA > At baseline TBI patients had significantly worse QoL-AGHDA scores compared with NFPA patients (13.8 vs 9.7). There was no association between time from injury and baseline QoL in the 51 patients in whom an injury date was recorded $(P=0.7)$. When reassessed 12 months after treatment commenced, QoL-AGHDA score had improved significantly in both groups, with the improvement being greater in the TBI patients (5.0 vs 3.5 points; $P=0.04$ ); however, the overall score remained worse in TBI patients (Fig. 3A).

Assessment of QoL: QoL-AGHDA dimensions • Data on dimensions at baseline are given in Table 1. At baseline, both TBI and NFPA patients showed impairment in all QoL-AGHDA dimensions. TBI patients had greater impairment in all areas compared with NFPA. TBI patients showed greatest impairment in tiredness, followed by tenseness, memory, self-confidence and lastly socialising. At 1 year, both groups of patients improved significantly in all areas. Self-confidence was the only dimension where patients with TBI improved to a significantly greater extent than patients with NFPA (Table 1).

The analysis was repeated in patients documented with 'severe' GHD. A total of 89 patients and 896 NFPA patients were eligible for inclusion in this analysis. In this group, there was no significant difference in peak GH after correction for age, gender, BMI and type of stimulation test. Although power was reduced due to smaller numbers, our key findings were unchanged.

\section{Analysis 3 (Group 3)}

QoL-AGHDA scores for 8 years post GH start were available in both sets of patients. These are shown in Fig. 3. In the TBI patients, the initial improvement in QoL observed after 12 months was sustained over the 8-year period; however, it remained significantly worse than that in the NFPA group (Fig. 3A). When compared with data from the general population, TBI patients had a significantly worse QoL score up until year 8 when this difference became non-significant (Fig. 3B).

Analysis of QoL-AGHDA dimensions showed that TBI patients demonstrated normalisation of socialisation compared with the normal population after 1 year. 


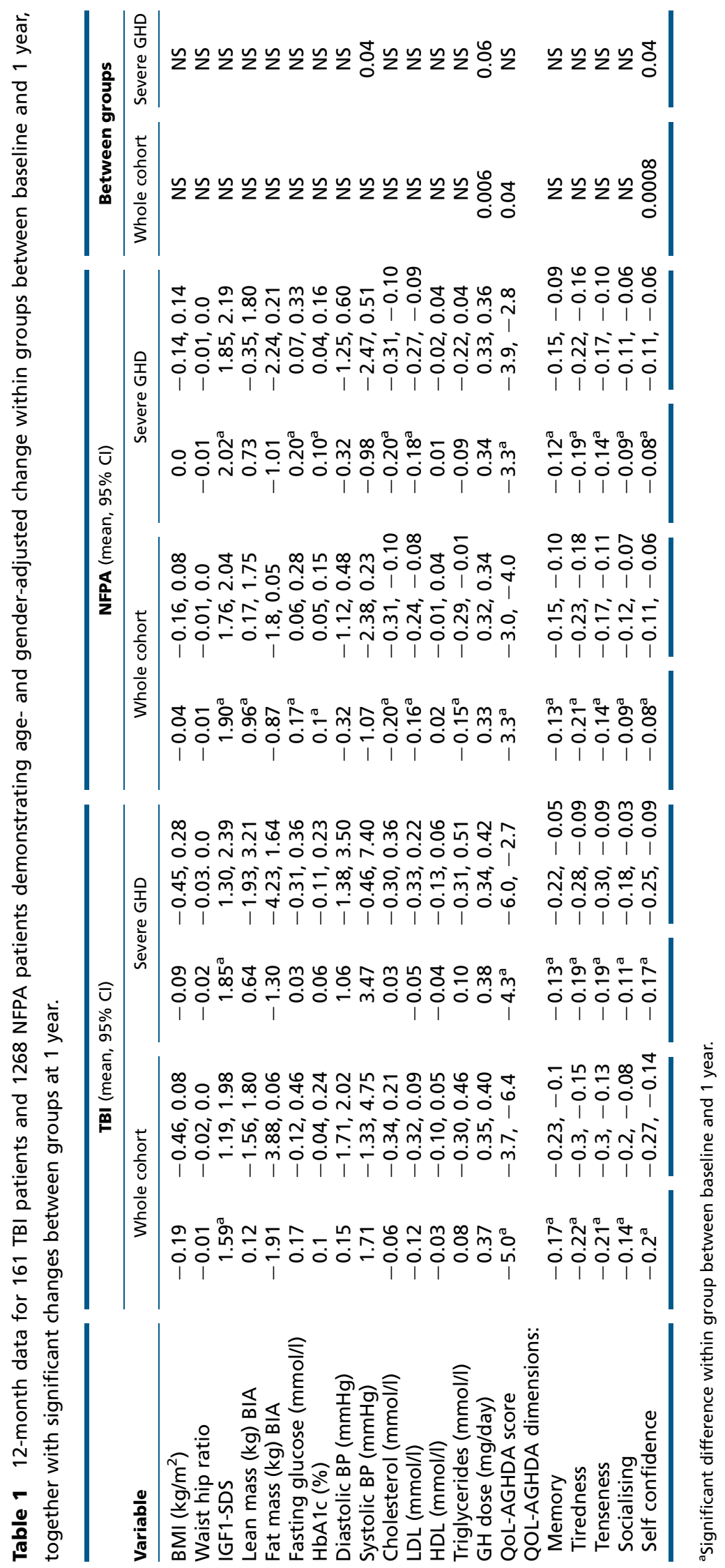




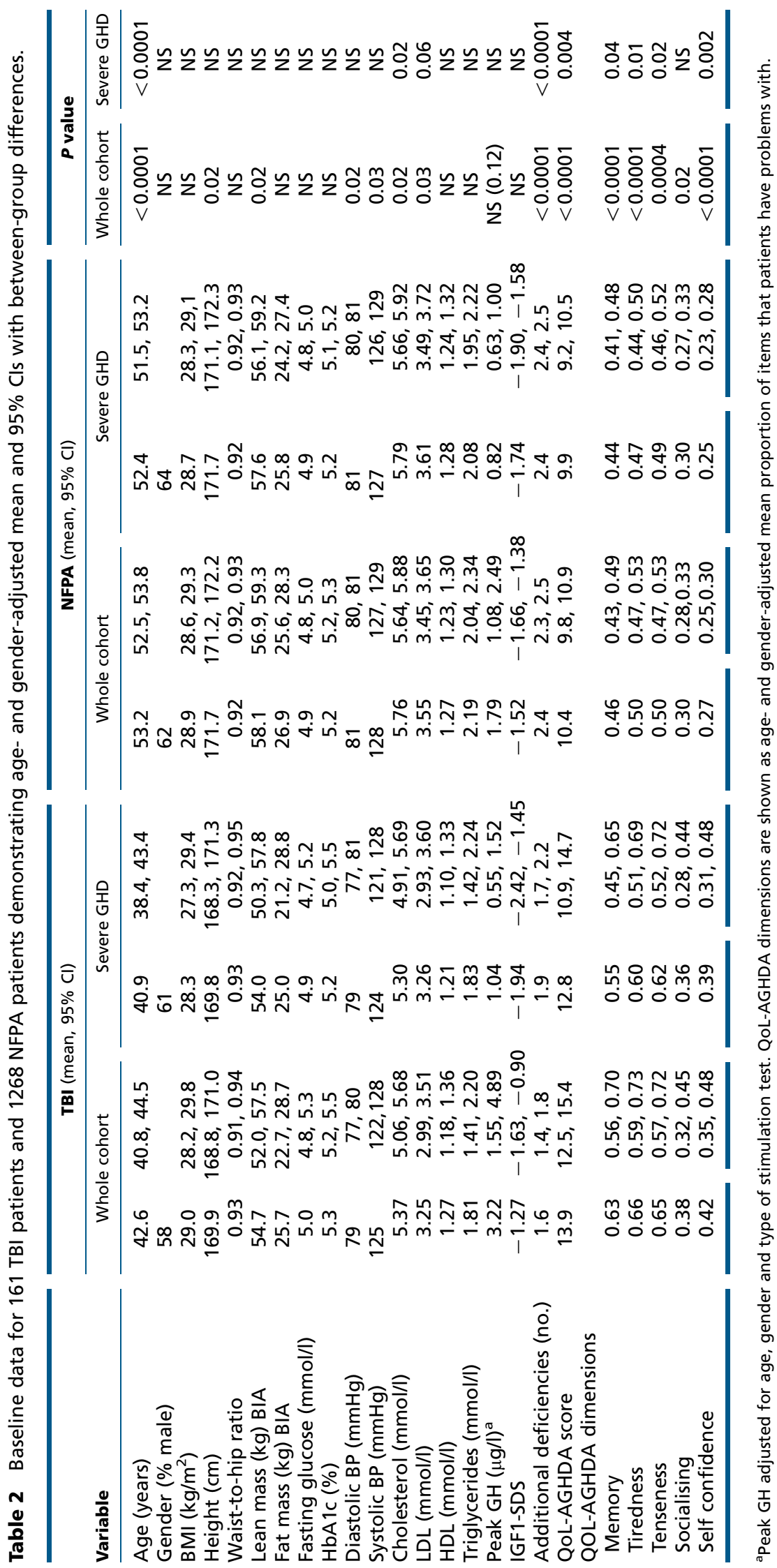




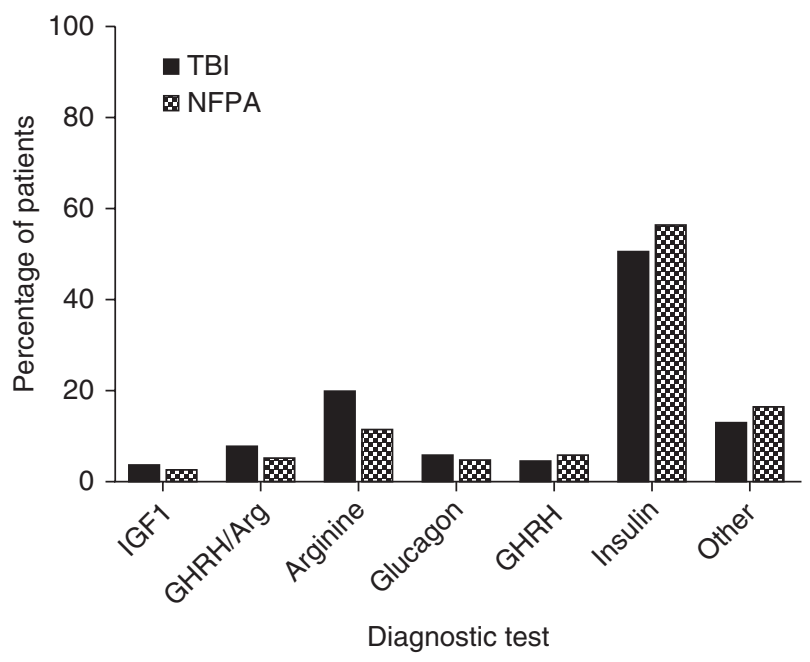

Figure 2

Growth hormone stimulation tests used for diagnosis of GHD in 161 TBI patients and 1268 NFPA patients.

Self-confidence returned to within the range of the normal population by year 6 as did tenseness, although small numbers led to wider CIs by this point. Impairment in tiredness and memory never returned to the level of the normal population (Fig. 4).

\section{Discussion}

In this analysis, we have examined the largest cohort of patients following TBI with 1-year follow-up data on a range of variables. We have additionally presented QoL data for 8 years post GHR and compared this with other patients with hypopituitarism due to another cause (NFPA), and with a reference population.

We have shown that the proportion of registrations for PTHP is increasing, but remains low (Supplementary Analysis, see section on supplementary data given at the end of this article). We had speculated that after the recent interest in PTHP, registrations for this cause of GHD would have increased. The incidence of hospitalised TBI patients is 235 per 100000 population (37). Considering a pooled prevalence of PTHP of $27.4 \%$ (95\% CI: $22.8-28.9 \%$ ) found by Schneider et al. (6), this could suggest that a large number of undiagnosed patients with GHD exist, although the meta-analysis does include data from highly selected cohorts, so prevalence may be overestimated.

Our second hypothesis, that with increased awareness, the lag time from injury to GHD diagnosis would have reduced, was not confirmed. We demonstrated once again a significant lag time between injury date and diagnosis of GHD, with patients with TBI diagnosed over 2 years later than NFPA patients. This lag was observed in the two previous KIMS studies $(24,25)$. It may be that a reduction in the lag time is observed in future studies.

We have shown that TBI patients with PTHP have a different hormonal and metabolic profile in comparison with hypopituitary patients with NFPA. Our analysis of the metabolic profile and nature of PTHP in this population has reconfirmed that the TBI population is younger, and of similar BMI to NFPA patients. Our analysis shows that the nature and risk of PTHP differ from that seen with NFPA. There is a higher incidence of isolated GHD, and a consequent reduction in the number of associated pituitary deficiencies, which could be considered suggestive of less severe hypopituitarism than in NFPA. This is also supported by the finding of a trend to higher peak
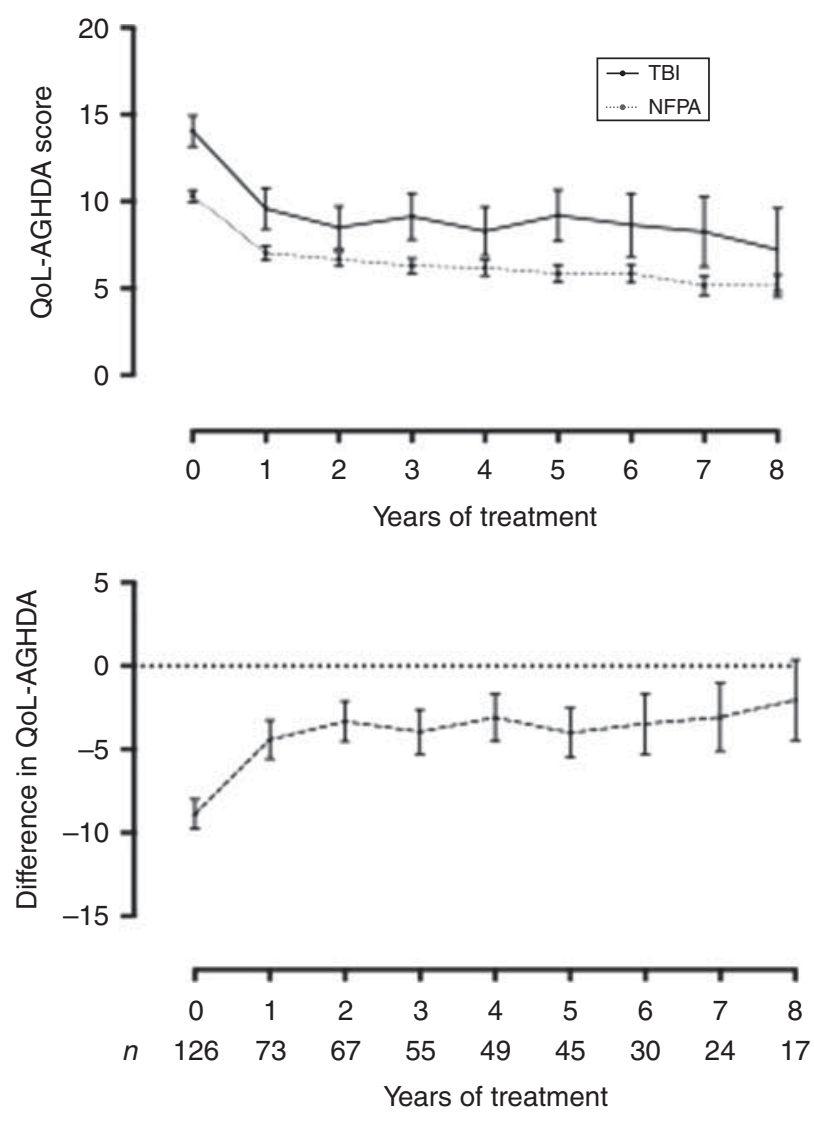

\section{Figure 3}

Changes in QoL-AGHDA score over time in patients given GHR.

(A) 154 TBI patients and 1143 NFPA patients at baseline and

(B) 126 TBI patients in whom country-specific normative data were available. Dotted line indicates level of normal population, $n$ equals number of TBI patients available for follow-up at each point. 


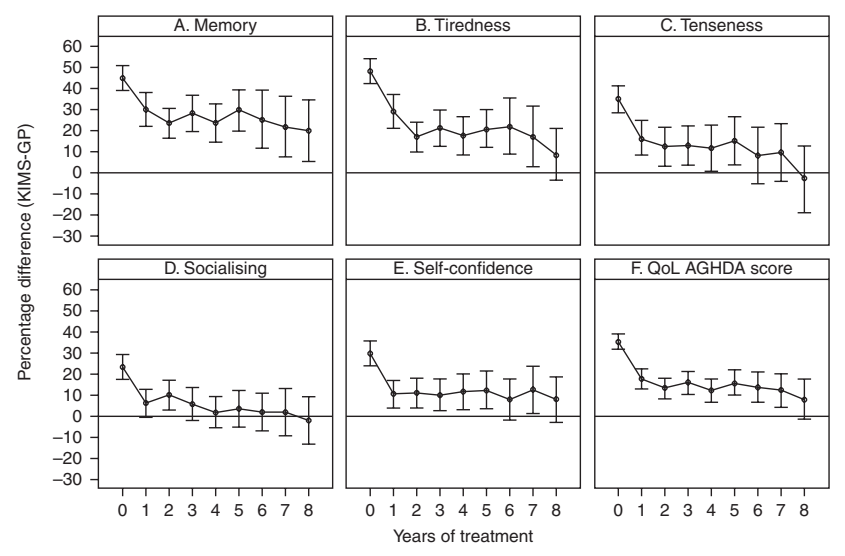

\section{Figure 4}

Percentage difference in AGHDA dimensions in comparison with general population (GP) in TBI patients (126 at baseline) in whom country-specific normative data were available. Higher percentage equals worse QoL for each specific dimension.

GH to stimulation in GHD patients, although this can partially be explained by differences in stimulation testing, with no significant difference in peak GH observed after correction for type of stimulation test. It could be postulated that healthy patients could have been misclassified as GHD which has been a concern in recent studies (38); however, we also observed similar pretreatment IGF1-SDS between the groups which would refute this. We have also demonstrated similar findings when the analysis has been repeated on patients with documented severe GHD as defined before (39), including taking account of BMI in the GHRH/Arginine test, the only test currently where BMI-specific cut-offs are available. The body composition and metabolic data of PTHP suggest a lower cardiovascular risk than in patients with NFPA, with lower cholesterol and LDL concentrations, and lower systolic and diastolic blood pressures even after correction for age and gender. The only marker of adverse body composition in the TBI group is the finding of lower lean muscle mass, which may represent disuse atrophy.

We have shown that similar to previous KIMS data $(24,25)$, patients post TBI were shorter than counterparts with NFPA. Subgroup analysis has shown that this difference can be accounted for by patients whose injury date was before 19 years of age (data not shown). This suggests that head injury in childhood when incurred before attainment of final height, may in some cases account for reductions in growth, although the numbers involved are small. However, Bellone et al. (40) demonstrated an association between reduced height velocity in children post TBI and PTHP in this group.

This study has provided initial evidence on the beneficial and sustained effect of GHR on QoL in this cohort over 8 years. It has been shown in many studies that TBI patients have reduced QoL, and that TBI patients with PTHP have a worse QoL and greater fatigue than compatriots without PTHP $(17,20,41,42)$, although this is not universally agreed (43). GHR is known to improve QoL in patients with GHD (33), and this is reconfirmed by the improvements in QoL seen in the NFPA patients in our study. Short-term studies and case reports have shown GHR to improve QoL and cognition in TBI patients with GHD up to 12 months $(44,45)$. Kozlowski et al. (21) demonstrated improvements in cognition, particularly verbal memory and in QoL after 12 months treatment, whilst Maric et al. (20) demonstrated improved cognitive abilities particularly in verbal and non-verbal memory, and improvements in psychiatric functioning with subsequent worsening in three patients who discontinued treatment for 12 months. Our data show significant improvement in QoL-AGHDA score after 12 months; however, additionally we have demonstrated sustained improvement over a number of years. There was no association between length of time since injury and baseline QoL which suggests that improvements in QoL were not simply due to increasing length of time since the injury rather than GHR.

Similar to previous data on changes in QoL-AGHDA dimensions in GHD patients treated with GHR (33), we have shown a more rapid improvement in problems with socialising, and a much slower improvement in problems with memory and tiredness. As would be expected QoL scores remain significantly lower than both NFPA patients and the reference population, most likely reflecting other consequences of injury in these patients. Recently it has been shown by Tanriverdi et al. (5) that hypopituitarism improves in a proportion of patients when pituitary function is rechecked 5 years post injury. This factor as well as overall physical recovery may be responsible for the continued gradual improvement in QoL after the initial 12-month period.

This study has several weaknesses. Our data cover only patients with GHD rather than the full spectrum of pituitary deficiencies without GHD. However, given that GHD is usually the first deficiency to occur due to the location of the somatotrophs within the pituitary, it would be expected that most patients with other pituitary hormone deficiencies would also have GHD. This study only includes patients commencing GH, which would 
indicate that patients, particularly in the UK would need to be symptomatic - this could lead to over-reporting of poor QoL scores compared with the overall population of patients with PTHP. The cross-sectional nature of such a registry-based study also means that there could be a bias to more positive outcomes, as patients who fail to improve may simply have dropped out. Furthermore, although concomitant medication was part of a standard KIMS data collection, the quality of information on other medication than pituitary hormone replacement does not allow for a meaningful analysis. Therefore, we could not correct our analyses for the impact of medications such as antidepressants. It must also be acknowledged that there are limitations when studying QoL as an outcome measure for TBI including poor definitions, lack of sensitivity and poor differentiation of the effect of comorbidities.

In conclusion, we have shown that registrations for PTHP are increasing, however remain proportionately lower than may be expected suggesting either underdiagnosis or failure to register patients. We have also demonstrated that compared with NFPA patients there remains a lag time between injury and diagnosis in TBI patients. Finally, our findings suggest that whilst PTHP may be biochemically less severe than hypopituitarism secondary to NFPA, there are significant and clinically relevant improvements in QoL, which are sustained in the long term in this population. These important findings provide an evidence base for treating affected patients with PTHP.

\section{Supplementary data}

This is linked to the online version of the paper at http://dx.doi.org/10.1530/ EJE-14-0654.

\section{Declaration of interest}

$M$ Korbonits received honoraria from Pfizer as member of the KIMS Strategic Advisory Board, A F Mattsson is permanent employee of Pfizer, $M$ Koltowska-Haggstrom was a full-time employee at Pfizer, Inc. when the work was done but now is an affiliate at the Department of Women's and Children's Health, Uppsala University, Uppsala, Sweden. C Daousi and D J Cuthbertson have both received unrestricted research grants from Pfizer. The authors were not paid for their contribution to this manuscript.

Funding

KIMS is sponsored by Pfizer, Inc.

\section{References}

1 Berg C, Oeffner A, Schumm-Draeger PM, Badorrek F, Brabant G, Gerbert B, Bornstein S, Zimmermann A, Weber M, Broecker-Preuss M et al. Prevalence of anterior pituitary dysfunction in patients following traumatic brain injury in a German multi-centre screening program. Experimental and Clinical Endocrinology \& Diabetes 2010118 139-144. (doi:10.1055/s-0029-1225611)

2 Kozlowski Moreau O, Yollin E, Merlen E, Daveluy W \& Rousseaux M. Lasting pituitary hormone deficiency after traumatic brain injury. Journal of Neurotrauma 201229 81-89. (doi:10.1089/neu.2011.2048)

3 Park KD, Kim DY, Lee JK, Nam HS \& Park YG. Anterior pituitary dysfunction in moderate-to-severe chronic traumatic brain injury patients and the influence on functional outcome. Brain Injury $2010 \mathbf{2 4}$ 1330-1335. (doi:10.3109/02699052.2010.506863)

4 Pavlovic D, Pekic S, Stojanovic M, Zivkovic V, Djurovic B, Jovanovic V, Miljic N, Medic-Stojanoska M, Doknic M, Miljic D et al. Chronic cognitive sequelae after traumatic brain injury are not related to growth hormone deficiency in adults. European Journal of Neurology 201017 696-702. (doi:10.1111/j.1468-1331.2009.02910.x)

5 Tanriverdi F, De Bellis A, Ulutabanca H, Bizzarro A, Sinisi AA, Bellastella G, Paglionico VA, Mora LD, Selcuklu A, Unluhizarci K et al. Five years prospective investigation of anterior pituitary function after traumatic brain injury: is hypopituitarism long-term after head trauma associated with autoimmunity? Journal of Neurotrauma $2013 \mathbf{3 0}$ 1426-1433. (doi:10.1089/neu.2012.2752)

6 Schneider HJ, Kreitschmann-Andermahr I, Ghigo E, Stalla GK \& Agha A. Hypothalamopituitary dysfunction following traumatic brain injury and aneurysmal subarachnoid hemorrhage: a systematic review. Journal of the American Medical Association 2007298 1429-1438. (doi:10.1001/jama.298.12.1429)

7 Schneider HJ, Schneider M, Kreitschmann-Andermahr I, Tuschy U, Wallaschofski H, Fleck S, Faust M, Renner CI, Kopczak A, Saller B et al. Structured assessment of hypopituitarism after traumatic brain injury and aneurysmal subarachnoid hemorrhage in 1242 patients: the German interdisciplinary database. Journal of Neurotrauma 201128 1693-1698. (doi:10.1089/neu.2011.1887)

8 Aimaretti G, Ambrosio MR, Di Somma C, Gasperi M, Cannavo S, Scaroni C, Fusco A, Del Monte P, De Menis E, Faustini-Fustini M et al. Residual pituitary function after brain injury-induced hypopituitarism: a prospective 12-month study. Journal of Clinical Endocrinology and Metabolism 200590 6085-6092. (doi:10.1210/ jc.2005-0504)

9 Klose M, Juul A, Poulsgaard L, Kosteljanetz M, Brennum J \& FeldtRasmussen U. Prevalence and predictive factors of post-traumatic hypopituitarism. Clinical Endocrinology 200767 193-201. (doi:10.1111/ j.1365-2265.2007.02860.x)

10 Agha A, Rogers B, Sherlock M, O'Kelly P, Tormey W, Phillips J \& Thompson CJ. Anterior pituitary dysfunction in survivors of traumatic brain injury. Journal of Clinical Endocrinology and Metabolism 200489 4929-4936. (doi:10.1210/jc.2004-0511)

11 Kelly DF, Gonzalo IT, Cohan P, Berman N, Swerdloff R \& Wang C. Hypopituitarism following traumatic brain injury and aneurysmal subarachnoid hemorrhage: a preliminary report. Journal of Neurosurgery 200093 743-752. (doi:10.3171/jns.2000.93.5.0743)

12 Kokshoorn NE, Smit JW, Nieuwlaat WA, Tiemensma J, Bisschop PH, Groote-Veldman R, Roelfsema F, Franken AA, Wassenaar MJ, Biermasz NR et al. Low prevalence of hypopituitarism after traumatic brain injury: a multicenter study. European Journal of Endocrinology 2011 165 225-231. (doi:10.1530/EJE-11-0365)

13 Leal-Cerro A, Flores JM, Rincon M, Murillo F, Pujol M, GarciaPesquera F, Dieguez C \& Casanueva FF. Prevalence of hypopituitarism and growth hormone deficiency in adults long-term after severe traumatic brain injury. Clinical Endocrinology 200562 525-532. (doi:10.1111/j.1365-2265.2005.02250.x)

14 Lieberman SA, Oberoi AL, Gilkison CR, Masel BE \& Urban RJ. Prevalence of neuroendocrine dysfunction in patients recovering from traumatic brain injury. Journal of Clinical Endocrinology and Metabolism 200186 2752-2756. (doi:10.1210/jcem.86.6.7592) 
15 Draper K \& Ponsford J. Cognitive functioning ten years following traumatic brain injury and rehabilitation. Neuropsychology 200822 618-625. (doi:10.1037/0894-4105.22.5.618)

16 Levin HS, Williams DH, Eisenberg HM, High WM Jr \& Guinto FC Jr. Serial MRI and neurobehavioural findings after mild to moderate closed head injury. Journal of Neurology, Neurosurgery, and Psychiatry 199255 255-262. (doi:10.1136/jnnp.55.4.255)

17 Kelly DF, McArthur DL, Levin H, Swimmer S, Dusick JR, Cohan P, Wang C \& Swerdloff R. Neurobehavioral and quality of life changes associated with growth hormone insufficiency after complicated mild, moderate, or severe traumatic brain injury. Journal of Neurotrauma 2006 23 928-942. (doi:10.1089/neu.2006.23.928)

18 Jeong JH, Kim YZ, Cho YW \& Kim JS. Negative effect of hypopituitarism following brain trauma in patients with diffuse axonal injury. Journal of Neurosurgery 2010113 532-538. (doi:10.3171/2009.10.JNS091152)

19 High WM Jr, Briones-Galang M, Clark JA, Gilkison C, Mossberg KA, Zgaljardic DJ, Masel BE \& Urban RJ. Effect of growth hormone replacement therapy on cognition after traumatic brain injury. Journal of Neurotrauma 201027 1565-1575. (doi:10.1089/neu.2009. 1253)

20 Maric NP, Doknic M, Pavlovic D, Pekic S, Stojanovic M, Jasovic-Gasic M $\&$ Popovic V. Psychiatric and neuropsychological changes in growth hormone-deficient patients after traumatic brain injury in response to growth hormone therapy. Journal of Endocrinological Investigation 2010 33 770-775. (doi:10.1007/BF03350340)

21 Kozlowski O, Cortet-Rudelli C, Yollin E, Merlen E, Daveluy W \& Rousseaux M. Growth hormone replacement therapy in patients with traumatic brain injury. Journal of Neurotrauma 201330 998-1006. (doi:10.1089/neu.2012.2705)

22 Kokshoorn NE, Wassenaar MJ, Biermasz NR, Roelfsema F, Smit JW, Romijn JA \& Pereira AM. Hypopituitarism following traumatic brain injury: prevalence is affected by the use of different dynamic tests and different normal values. European Journal of Endocrinology 2010162 11-18. (doi:10.1530/EJE-09-0601)

23 Gardner CJ, Javadpour M, Stoneley C, Purthuran M, Biswas S, Daousi C, MacFarlane IA \& Cuthbertson DJ. Low prevalence of hypopituitarism after subarachnoid haemorrhage using confirmatory testing and with BMI-specific GH cut-off levels. European Journal of Endocrinology 2013 168 473-481. (doi:10.1530/EJE-12-0849)

24 Casanueva FF, Leal A, Koltowska-Haggstrom M, Jonsson P \& Goth MI. Traumatic brain injury as a relevant cause of growth hormone deficiency in adults: a KIMS-based study. Archives of Physical Medicine and Rehabilitation 200586 463-468. (doi:10.1016/j.apmr.2004.05.018)

25 Kreitschmann-Andermahr I, Poll EM, Reineke A, Gilsbach JM, Brabant G, Buchfelder M, Fassbender W, Faust M, Kann PH \& Wallaschofski H. Growth hormone deficient patients after traumatic brain injury - baseline characteristics and benefits after growth hormone replacement - an analysis of the German KIMS database. Growth Hormone \& IGF Research 200818 472-478. (doi:10.1016/j.ghir. 2008.08.007)

26 Gutierrez LP, Koltowska-Haggstrom M, Jonsson PJ, Mattsson AF, Svensson D, Westberg B \& Luger A. Registries as a tool in evidencebased medicine: example of KIMS (Pfizer International Metabolic Database). Pharmacoepidemiology and Drug Safety 200817 90-102. (doi:10.1002/pds.1510)

27 Corneli G, Di Somma C, Baldelli R, Rovere S, Gasco V, Croce CG, Grottoli S, Maccario M, Colao A, Lombardi G et al. The cut-off limits of the GH response to GH-releasing hormone-arginine test related to body mass index. European Journal of Endocrinology 2005153 257-264. (doi:10.1530/eje.1.01967)

28 McKenna SP, Doward LC, Alonso J, Kohlmann T, Niero M, Prieto L \& Wiren L. The QoL-AGHDA: an instrument for the assessment of quality of life in adults with growth hormone deficiency. Quality of Life Research 19998 373-383. (doi:10.1023/A:1008987922774)

29 Wiren L, Whalley D, McKenna S \& Wilhelmsen L. Application of a disease-specific, quality-of-life measure (QoL-AGHDA) in growth hormone-deficient adults and a random population sample in Sweden: validation of the measure by rasch analysis. Clinical Endocrinology 2000 52 143-152. (doi:10.1046/j.1365-2265.2000.00899.x)

30 Moock J, Friedrich N, Volzke H, Spielhagen C, Nauck M, KoltowskaHaggstrom M, Buchfelder M, Wallaschofski H \& Kohlmann T. Prediction of improvement in quality of life (QoL-AGHDA) in adults with growth hormone deficiency by normative reference limits: data of the German KIMS cohort. Growth Hormone \& IGF Research 201121 272-278. (doi:10.1016/j.ghir.2011.07.005)

31 Busschbach JJ, Wolffenbuttel BH, Annemans L, Meerding WJ \& Koltowska-Haggstrom M. Deriving reference values and utilities for the QoL-AGHDA in adult GHD. European Journal of Health Economics 201112 243-252. (doi:10.1007/s10198-010-0241-7)

32 Gilet H, Chachuat A, Viala-Danten M, Auziere S \& KoltowskaHaggstrom M. Application of the disease-specific Quality of Life Assessment of Growth Hormone Deficiency in Adults (QoL-AGHDA) questionnaire in a general population: results from a French panel study. Value in Health 201013 495-500. (doi:10.1111/j.1524-4733.2009.00689.x)

33 Koltowska-Haggstrom M, Mattsson AF, Monson JP, Kind P, Badia X, Casanueva FF, Busschbach J, Koppeschaar HP \& Johannsson G. Does long-term GH replacement therapy in hypopituitary adults with GH deficiency normalise quality of life? European Journal of Endocrinology 2006155 109-119. (doi:10.1530/eje.1.02176)

34 Underwood L \& Murphy M. Radioimmunoassay of the somatomedins/ insulin-like growth factors. In Radioimmunoassay in Basic and Clincal Pharmacology, pp 561-574. Eds C Patrano \& B Peskar. Berlin: SpringerVerlag. (doi:10.1007/978-3-642-71809-0_23)

35 Brabant G, von zur Muhlen A, Wuster C, Ranke MB, Kratzsch J, Kiess W, Ketelslegers JM, Wilhelmsen L, Hulthen L, Saller B et al. Serum insulinlike growth factor I reference values for an automated chemiluminescence immunoassay system: results from a multicenter study. Hormone Research 200360 53-60. (doi:10.1159/000071871)

36 Abs R, Bengtsson BA, Hernberg-Stahl E, Monson JP, Tauber JP, Wilton P \& Wuster C. GH replacement in 1034 growth hormone deficient hypopituitary adults: demographic and clinical characteristics, dosing and safety. Clinical Endocrinology 199950 703-713. (doi:10.1046/ j.1365-2265.1999.00695.x)

37 Tagliaferri F, Compagnone C, Korsic M, Servadei F \& Kraus J. A systematic review of brain injury epidemiology in Europe. Acta Neurochirurgica 2006148 255-268. (doi:10.1007/s00701-005-0651-y)

38 Klose M, Stochholm K, Janukonyte J, Lehman Christensen L, Frystyk J, Andersen M, Laurberg P, Christiansen JS \& Feldt-Rasmussen U. Prevalence of posttraumatic growth hormone deficiency is highly dependent on the diagnostic set-up: results from The Danish National Study on Posttraumatic Hypopituitarism. Journal of Clinical Endocrinology and Metabolism 201499 101-110. (doi:10.1210/jc.2013-2397)

39 Tritos NA, Greenspan SL, King D, Hamrahian A, Cook DM, Jönsson PJ, Wajnrajch MP, Koltowska-Häggstrom M \& Biller BM. Unreplaced sex steroid deficiency, corticotropin deficiency, and lower IGF-I are associated with lower bone mineral density in adults with growth hormone deficiency: a KIMS database analysis. Journal of Clinical Endocrinology and Metabolism 201196 1516-1523. (doi:10.1210/jc.2010-2662)

40 Bellone S, Einaudi S, Caputo M, Prodam F, Busti A, Belcastro S Parlamento S, Zavattaro M, Verna F, Bondone C et al. Measurement of height velocity is an useful marker for monitoring pituitary function in patients who had traumatic brain injury. Pituitary 201316 499-506. (doi:10.1007/s11102-012-0446-0)

41 Bushnik T, Englander J \& Katznelson L. Fatigue after TBI: association with neuroendocrine abnormalities. Brain Injury 200721 559-566. (doi:10.1080/02699050701426915)

42 Srinivasan L, Roberts B, Bushnik T, Englander J, Spain DA, Steinberg GK, Ren L, Sandel ME, Al-Lawati Z, Teraoka J et al. The impact of hypopituitarism on function and performance in subjects with recent history of traumatic brain injury and aneurysmal subarachnoid haemorrhage. Brain Injury 200923 639-648. (doi:10.1080/ 02699050902970778) 
43 Ulfarsson T, Arnar Gudnason G, Rosen T, Blomstrand C, Stibrant Sunnerhagen K, Lundgren-Nilsson A \& Nilsson M. Pituitary function and functional outcome in adults after severe traumatic brain injury: the long-term perspective. Journal of Neurotrauma 201330 271-280. (doi:10.1089/neu.2012.2494)

44 Bhagia V, Gilkison C, Fitts RH, Zgaljardic DJ, High WM Jr, Masel BE, Urban RJ \& Mossberg KA. Effect of recombinant growth hormone replacement in a growth hormone deficient subject recovering from mild traumatic brain injury: a case report. Brain Injury 201024 560-567. (doi:10.3109/02699051003601705)

45 Tanriverdi F, Unluhizarci K, Karaca Z, Casanueva FF \& Kelestimur F. Hypopituitarism due to sports related head trauma and the effects of growth hormone replacement in retired amateur boxers. Pituitary 2010 13 111-114. (doi:10.1007/s11102-009-0204-0)

Received 4 August 2014

Revised version received 1 December 2014

Accepted 23 December 2014 